\title{
Sulphur based thermochemical cycles: Development and assessment of key components of the process
}

\author{
M. Roeb ${ }^{a, *}$, D. Thomey ${ }^{a}$, L. de Oliveira ${ }^{a}$, C. Sattler $^{a}$, G. Fleury $^{b}$, F. Pra $^{b}$, \\ P. Tochon ${ }^{b}$, A. Brevet ${ }^{b}$, G. Roux ${ }^{b}$, N. Gruet ${ }^{e}$, C. Mansilla ${ }^{c}$, F. LeNaour ${ }^{b}$, S. Poitou ${ }^{d}$, \\ R.W.K. Allen ${ }^{f}$, R. Elder $^{f}$, G. Kargiannakis ${ }^{g}$, C. Agrafiotis ${ }^{g}$, A. Zygogianni ${ }^{g}$, \\ C. Pagkoura ${ }^{g}$, A.G. Konstandopoulos ${ }^{g}$, A. Giaconia ${ }^{h}$, S. Sau ${ }^{h}$, P. Tarquini ${ }^{h}$, \\ S. Haussener ${ }^{i}$, A. Steinfeld ${ }^{i}$, I. Canadas ${ }^{j}$, A. Orden ${ }^{j}$, M. Ferrato $^{k}$ \\ ${ }^{a}$ Deutsches Zentrum für Luft- und Raumfahrt e.V. (DLR), Solar Research, Linder Höhe, 51147 Köln, Germany \\ ${ }^{\mathrm{b}}$ Commissariat à l'énergie atomique et aux énergies alternatives, CEA-Grenoble, DRT/LITEN, 17 Rue des Martyrs, \\ F-38054 Grenoble, France \\ ${ }^{\mathrm{C}}$ CEA-Saclay, DEN, I-tésé, F-91191 Gif-sur-Yvette, France \\ ${ }^{d}$ CEA-Cadarache, DEN/DTN, 13108 Saint-Paul-les-Durance, France \\ ${ }^{\text {e }}$ CEA-Saclay, DEN/DANS/DPC, 91191 Gif-sur-Yvette, France \\ ${ }^{\mathrm{f}}$ University of Sheffield, Chemical and Biological Engineering, Mappin Street, Sheffield S1 3JD, United Kingdom \\ ${ }^{g}$ Aerosol and Particle Technology Lab. (APTL), Centre for Research and Technology Hellas, 6th km Harilaou-Thermi Road, \\ 57001 Thessaloniki, Greece \\ ${ }^{\mathrm{h}}$ ENEA, Casaccia Research Center, Via Anguillarese, 301, 00060 Rome, Italy \\ ${ }^{\mathrm{i}}$ Eidgenössische Technische Hochschule Zürich, Energy Science Center, Sonneggstrasse 3, 8092 Zürich, Switzerland \\ ${ }^{j}$ Empresarios Agrupados, Magallanes 3, 28015 Madrid, Spain \\ ${ }^{\mathrm{k}}$ Mersen - Boostec Industries, Zone Industrielle, 65460 Bazet, France
}

\section{A R T I C L E I N F O}

Article history:

Received 12 September 2012

Received in revised form

8 January 2013

Accepted 10 January 2013

Available online 8 February 2013

Keywords:

Hydrogen production

Thermochemical cycles

Sulphuric acid decomposition

Heat exchanger

Silicon carbide

Solar tower

\section{A B S T R A C T}

HycycleS was a cooperation of nine European partners and further non-European partners and aimed at the qualification and enhancement of materials and components for key steps of solar and nuclear powered thermochemical cycles for hydrogen generation from water. The focus of HycycleS was the decomposition of sulphuric acid $\left(\mathrm{H}_{2} \mathrm{SO}_{4}\right)$ which is the central step of the sulphur-based family of those processes. Emphasis was put on materials and components for $\mathrm{H}_{2} \mathrm{SO}_{4}$ evaporation, decomposition, and sulphur dioxide separation. The suitability of materials and components was demonstrated by decomposing $\mathrm{H}_{2} \mathrm{SO}_{4}$ and separating its decomposition products in scalable prototypes.

Silicon Carbide $(\mathrm{SiC})$ turned out as the material of choice for the components facing the most corrosive environment of the process: the sulphuric acid evaporator and decomposer. Candidate catalysts for the high temperature reduction of sulphur trioxide have been screened and analysed. $\mathrm{Cr}-\mathrm{Fe}$ mixed oxide $\left(\mathrm{Fe}_{0.7} \mathrm{Cr}_{1.3} \mathrm{O}_{3}\right)$ was the most promising material among the ones examined.

Based on the use of the highlighted construction and catalyst materials prototype decomposers have been developed and tested. The successful fabrication and testing of a large size heat exchanger/reactor prototype composed of $\mathrm{SiC}$ plates shows promise with respect to its use for $\mathrm{H}_{2} \mathrm{SO}_{4}$ decomposition in the $\mathrm{SI}$ and HyS cycle. A solar specific

\footnotetext{
* Corresponding author. Tel.: +49 2203601 2673; fax: +49 22036014141.

E-mail address: martin.roeb@dlr.de (M. Roeb).

0360-3199/\$ - see front matter Copyright @ 2013, Hydrogen Energy Publications, LLC. Published by Elsevier Ltd. All rights reserved. http://dx.doi.org/10.1016/j.ijhydene.2013.01.068
} 
decomposer prototype was developed, realised and successfully tested on sun in a solar furnace.

A novel approach of using dense oxygen transport membranes, made from complex ceramics, for oxygen removal from the $\mathrm{H}_{2} \mathrm{SO}_{4}$ decomposition product in order to shift the equilibrium in favour of increased decomposition was investigated. The membranes stability and suitability for carrying out this separation was investigated experimentally. Parallel to this, a conventional oxygen separator, a low-temperature wet scrubbing system, was investigated as well. Scale-up scenarios of components and of the process were addressed.

Copyright @ 2013, Hydrogen Energy Publications, LLC. Published by Elsevier Ltd. All rights reserved.

\section{Introduction}

The technical challenges in achieving a technical and economically feasible $\mathrm{CO}_{2}$-free hydrogen production are significant, but the development of emission-free hydrogen production technologies is essential to the long-term viability of a hydrogen economy. Solar and nuclear energy have the potential to play a major role in assuring a secure and environmentally sound source of transportation fuels. The fundamental challenge is to focus research and development on those processes which have the highest probability of producing hydrogen at competitive costs.

Thermochemical methods have the potential to achieve this objective [1,2]. Small-scale experimental precursors to the integrated laboratory-scale experiments have been operated successfully to date and continue to show promise for largerscale systems. Nevertheless some bottlenecks still have to be overcome.

These processes offer the potential for highly efficient hydrogen production at large-scale, but most processes have only been evaluated theoretically and therefore the technology is not ready for application yet. A high R\&D effort worldwide is dedicated to the sulphur-based cycles, i.e. sulphur-iodine (SI) and hybrid sulphur cycle (HyS) powered by solar or nuclear energy [3-5]. Those cycles are considered the prime processes for potential application as stated by a screening carried out under the U.S. Department of Energy (DOE) Hydrogen Program [6].

The major challenges of sulphur-based cycles are the high temperatures and corrosive environments present in their key steps [7]. The conditions require advanced materials for the key components and therefore special design and fabrication methods for those components. The key components that both cycles have in common include the oxygen separator, the $\mathrm{H}_{2} \mathrm{SO}_{4}$ evaporator and the sulphur trioxide $\left(\mathrm{SO}_{3}\right)$ decomposer. The latter has to withstand the highest temperature present in these cycles $\left(>850^{\circ} \mathrm{C}\right)$.

The objective of Hycycles project was to provide detailed solutions for the design of specific key components, and in particular on the materials needed. Thus, the focus of Hycycles was one of the most challenging sections of the plant and one which is common to both processes: the high temperature section for the thermal decomposition of sulphuric acid. The materials of interest comprise corrosion and high temperature resistant construction materials for the mentioned components and catalyst systems capable to achieve the required process performance of the high temperature $\mathrm{SO}_{3}$ reduction.

\section{Results and discussion}

Due to the broad spectrum of the aspects addressed during the project in this paper only a few can be highlighted and the presentation of experimental and simulation results is only exemplary.

\subsection{Advanced construction materials for the production of $\mathrm{SO}_{2}$ from $\mathrm{H}_{2} \mathrm{SO}_{4}$}

Sulphuric acid and its decomposition products impose a challenge for materials used to set up the units and components of the process, in particular if considering the elevated temperature level, the corrosiveness of fluids and the phase changes involved. Therefore, mechanical performance and corrosion resistance issues of advanced construction materials for the production of sulphur dioxide $\left(\mathrm{SO}_{2}\right)$ from $\mathrm{H}_{2} \mathrm{SO}_{4}$ were addressed. Specifically, $\mathrm{SiC}$ based ceramic materials, their brazed joints and coated catalyst systems under thermochemical decomposition conditions in sulphur-based thermochemical cycles have been investigated for the assessment of their extended use in high temperature corrosive environments. This is to validate the materials composition, and fabrication and joining methods for improved performance and reliability.

Particular emphasis was placed on analysing SiC-based materials of possible use for the plate heat exchangerreactor and the solar receiver-reactor as $\mathrm{H}_{2} \mathrm{SO}_{4}$ evaporator/ decomposer. Two different corrosion test campaigns, i.e. exposures to $\mathrm{SO}_{2}$ and $\mathrm{SO}_{3}$ rich environments, have been conducted corresponding to the conditions at the outlet and the inlet of a decomposer, respectively. Runs at up to $1000 \mathrm{~h}$ exposure to $\mathrm{SO}_{2}$ and $\mathrm{SO}_{3}$ rich environment have been performed. Moreover, exposure to boiling sulphuric acid at up to $5000 \mathrm{~h}$ was performed to assess the materials performance with respect to the evaporator.

The formation of corrosive layers on the specimen surfaces goes along with weight gain of the material, since the layers adhere to the surface. The mechanical properties of the composite systems are not significantly affected by the 
corrosion process. Additional thermal cycling test results showed that cyclic heating had no additional effect after the exposures to the $\mathrm{SO}_{2}$ and $\mathrm{SO}_{3}$ rich corrosive environments. $\mathrm{SiC}$ and in particular siliconised $\mathrm{SiC}(\mathrm{SiSiC})$ proved to be suitable as a construction material in solar reactors for thermal decomposition of sulphuric acid, even after more than $5000 \mathrm{~h}$ of exposure. The conditions applied and more details on the behaviour of the samples under the relevant conditions are described in Ref. [8].

\subsection{Advanced catalysts and coatings for the decomposition of $\mathrm{H}_{2} \mathrm{SO}_{4}$}

Candidate catalysts for the high temperature decomposition of sulphur trioxide have been screened and analysed - mainly considering single and mixed oxides of transition metals. Their catalytic activity and their durability has been investigated and quantified experimentally.

Several single, binary and ternary oxides were prepared and characterised in the form of powders. Most of the candidate-catalysts prepared were single-phase materials of either spinel or perovskite structure.

Among the materials evaluated in a dedicated test rig, $\mathrm{Cu}-\mathrm{Fe}, \mathrm{Cu}-\mathrm{Al}, \mathrm{Cu}-\mathrm{Fe}-\mathrm{Al}, \mathrm{Cr}-\mathrm{Fe}$ and 'in-house' synthesised $\mathrm{Fe}_{2} \mathrm{O}_{3} / \mathrm{CuO} / \mathrm{Cr}_{2} \mathrm{O}_{3}$ showed initial activities that were significantly higher than the one measured for a commercial $\mathrm{Fe}_{2} \mathrm{O}_{3}$ grade (see Fig. 1) [9]. Most of these materials were found to have initial activities comparable to the one measured for the standard highly active $\mathrm{Pt} / \mathrm{Al}_{2} \mathrm{O}_{3}$ catalyst as described in Ref. [10], which also gives more details on the boundary conditions applied.

Additionally, experimental parametric campaigns with catalysts based on transition metal oxides and coated on SiSiC fragments were conducted with the aim of deriving suitable kinetic models. The parameters varied were temperature, weight hourly space velocity, pressure and catalyst particles size. This extensive study led to the evaluation of the effect of different operating parameters and also to the derivation of a simplified kinetic law suitable for the decomposer design. A first order kinetic law could ensure a suitable fit of the experimental data for the different catalysts investigated.

Based on the systematic studies on quantitative evaluation of the catalytic activity, durability and stability of the candidate catalysts investigated as well as on the conclusions drawn from the ex-situ post-characterisation activities, it is concluded that the $\mathrm{Cr}-\mathrm{Fe}$ mixed oxide $\left(\mathrm{Fe}_{0.7} \mathrm{Cr}_{1.3} \mathrm{O}_{3}\right)$ is the most promising material among the ones examined. This conclusion is mostly based on the chemical stability of the coating after post-characterisation and by making the logical assumption that a suitable catalyst for a long-term operation of a potential industrial scale process should remain chemically and structurally unaffected [11]. The latter is an important project achievement since it was demonstrated that stable $\mathrm{Cr}-\mathrm{Fe}$ mixed oxides can be prepared by the synthesis method employed and that the $\mathrm{Cr}$ leaching problems addressed in the literature so far could potentially be overcome.

\subsection{SiC plate heat exchanger as $\mathrm{H}_{2} \mathrm{SO}_{4}$ decomposer}

A main task of the project was the design, fabrication, and test of a compact $\mathrm{SiC}$ plate heat exchanger to be used as $\mathrm{SO}_{3}$ decomposer. To be able to build a large SiC plate heat exchanger reactor representative of the size to be used in a hydrogen production plant, its development was structured in 3 steps:

- Thermal design of the heat exchanger reactor,

- Development of the brazing techniques on small mock-ups, fabrication of the connectors and test of the mock-ups,

- Fabrication of the prototype, its connection system with the testing loop and realisation of the tests.

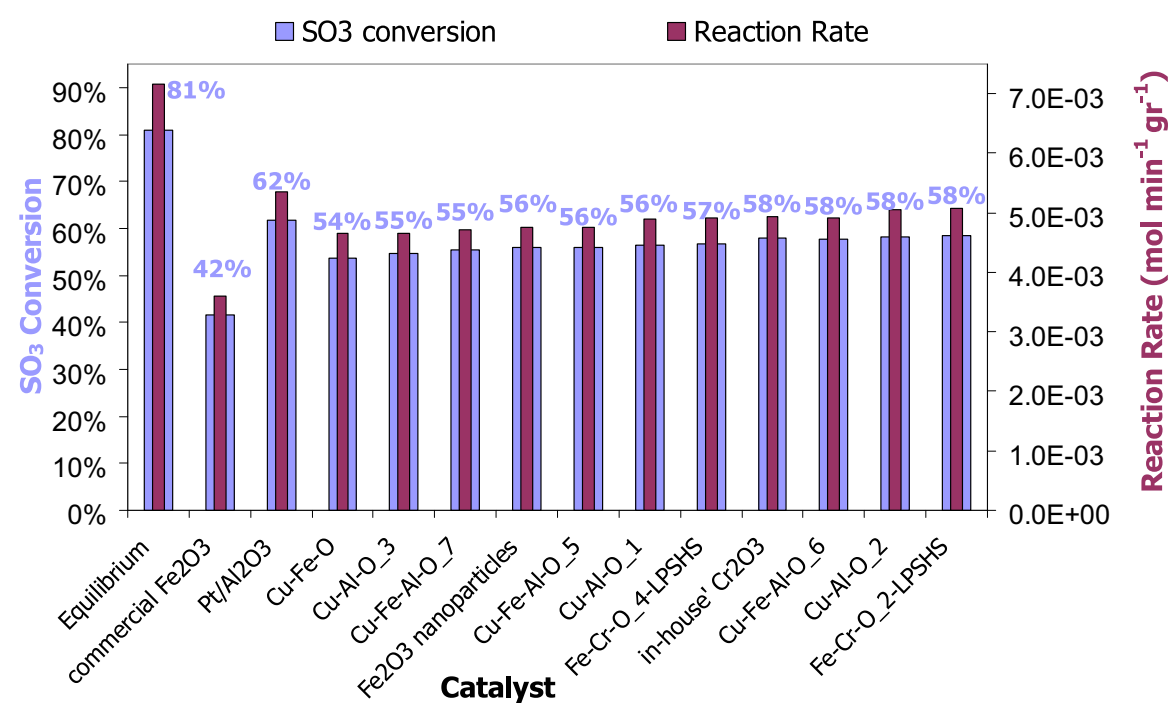

Fig. 1 - Comparative initial catalytic activity of the most promising materials evaluated under the following conditions: substrate: $\mathrm{SiC}$, temperature: $850{ }^{\circ} \mathrm{C}, \mathrm{P}=1 \mathrm{~atm}$, catalyst loading: $0.23-0.5 \mathrm{~g}$ of powder, $\mathrm{H}_{2} \mathrm{SO}_{4}$ flow (liquid): $0.11-0.24 \mathrm{ml} / \mathrm{min}$, nitrogen flow (for reactor-outlet dilution): $0.5-3.8 \mathrm{l} / \mathrm{min}$ (std), heated lines: $185-200{ }^{\circ} \mathrm{C}$, Experiment duration: $\sim 45 \mathrm{~min}$, Weight Hourly Space Velocity (WHSV): $50-52 \mathrm{~h}^{-1}$. 
The thermal design of the heat exchanger reactor targeted a large heat transfer area between the catalyst and the fluid, a large volumetric heat transfer coefficient, a plug-flow behaviour together with a suitable residence time for a given catalyst. A thermal design optimisation was made taking into consideration the specific fabrication constraints of SiC. The catalyst is integrated by filling coated bowls into the relevant channels to enable performing on-site the regeneration of the catalyst.

Two general designs were considered and investigated. The Multiple Adiabatic Reactor (MAR) design consists of reactor beds which contain the catalyst placed in series. The heat transfer is realised discretely between two different compartments of the reactor. The reactants enter alternately into sections for heat transfer and sections for catalytic reaction. The Catalyst Bed Reactor (CBR) design consists of channels placed in parallel. In this case, the heat transfer is performed continuously.

Thermohydraulics and thermomechanical calculations identified the CBR design as preferable, since it allows a higher residence time than the MAR design for the same HX reactor volume. The effective length is much longer due to channel geometry, whereas the calculated normal stresses of 25 and $20 \mathrm{MPa}$, respectively was in the same order of magnitude for both designs.

Small mock-ups were fabricated to validate the model predictions and to define suitable brazing parameters and necessary correlations for the fabrication of the full size heat exchanger reactor. Based on the previously described results and preparatory work, a large size prototype $\left(0.75 \times 0.19 \times 0.3 \mathrm{~m}^{3}\right)$ was fabricated based on the CBR design concept and following the fabrication route illustrated in Fig. 2.

Once fabricated, the SiC prototype was mounted on a testing rig to evaluate both its thermal efficiency and its mechanical stability. As shown in Fig. 3, the experimental thermal efficiency measured on the prototype was found to be very close to the theoretical efficiency of a pure counter-flow heat exchanger, validating the efficiency of the overall thermal design.

The successful fabrication and testing of a large size heat exchanger/reactor prototype composed of $\mathrm{SiC}$ plates shows promise with respect to its use for sulphuric acid decomposition in the SI and HyS cycles. This prototype represents one of the largest ceramic heat exchangers ever constructed.

\subsection{Solar receiver-reactor as $\mathrm{H}_{2} \mathrm{SO}_{4}$ decomposer}

As a concept for a direct coupling of concentrated solar radiation into the process, a multi-chamber reactor was chosen allowing the adaptation of each part of the reactor to the requirements of both evaporation and decomposition reactions so that these two sub-processes are performed separately (Fig. 4). Such a concept is advantageous when considering a future scale-up for a solar tower application. A multi-chamber reactor with two different temperature levels can exploit the energy input on a solar tower more efficiently than a singlechamber requiring a more uniform heat flux distribution [12]. The reactions in the two chambers have different reaction enthalpies and require different operating temperatures:

$$
\text { Evaporation: } \begin{array}{r}
\mathrm{H}_{2} \mathrm{SO}_{4(\mathrm{aq})} \rightarrow \mathrm{H}_{2} \mathrm{SO}_{4(\mathrm{~g})} \rightarrow \mathrm{SO}_{3(\mathrm{~g})}+\mathrm{H}_{2} \mathrm{O}_{(\mathrm{g})} \\
\mathrm{T}=350-400^{\circ} \mathrm{C}
\end{array}
$$

$\mathrm{SO}_{3}$ reduction : $\quad \mathrm{SO}_{3(\mathrm{~g})} \rightarrow \mathrm{SO}_{2(\mathrm{~g})}+\frac{1}{2} \mathrm{O}_{2(\mathrm{~g})} \quad \mathrm{T}=700-1000^{\circ} \mathrm{C}$

Consequently, the conditions needed for the evaporator and the decomposer differ considerably. Therefore, the reactor design for a prototype solar receiver-reactor includes two different chambers operating at different conditions: one for the evaporation of the acid and the second for the $\mathrm{SO}_{3}$ reduction.

The reactor has been constructed and installed at DLR's solar furnace in Cologne. Several test series have already been carried out and proved the suitability of all reactor components. Moreover, sulphuric acid was successfully decomposed to provide the required $\mathrm{SO}_{2}$ product with yields of up to $90 \%$ of the thermodynamic limit and with reactor efficiencies of up to $40 \%$. In Ref. [13] the boundary conditions, the experimental procedure and the results are described in more detail.

Design activities and experimental series were accompanied and supported by different methods of reactor and process simulation. The accurate knowledge of its effective heat/mass transport properties is crucial for the optimal design and operation of the solar evaporator part. Structure and dimensions of the foam must allow for an efficient evaporation, while avoiding reduced heat transfer at the Leidenfrost point.

The heat and mass transfer properties of the foam were determined. Computer tomography in conjunction with numerical techniques was used to determine the morphological
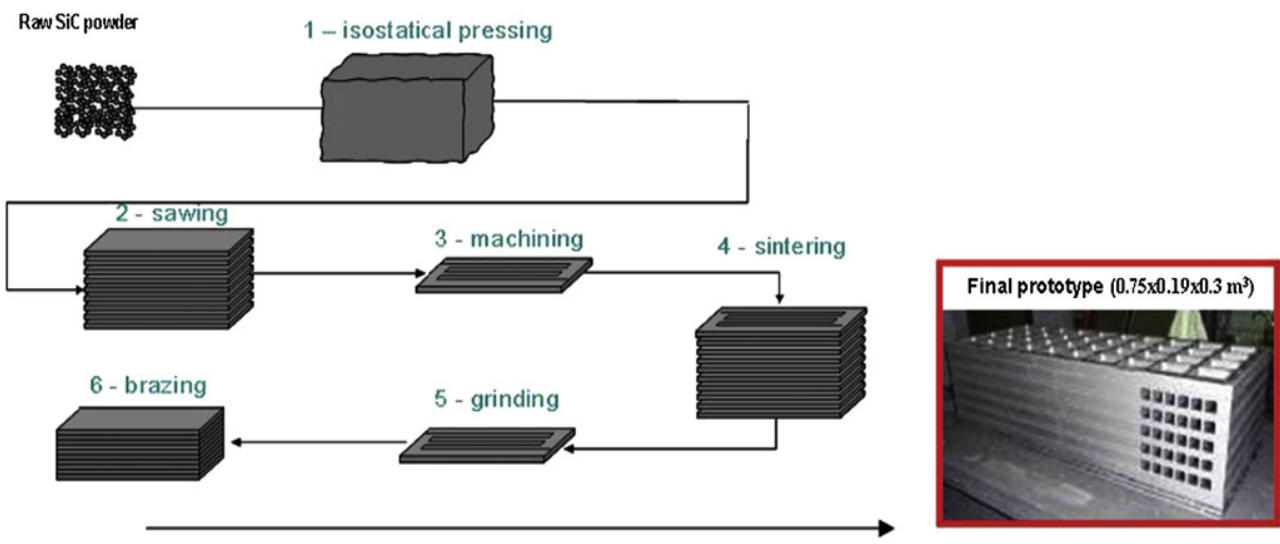

Fig. 2 - SiC compact heat exchanger prototype fabrication. 


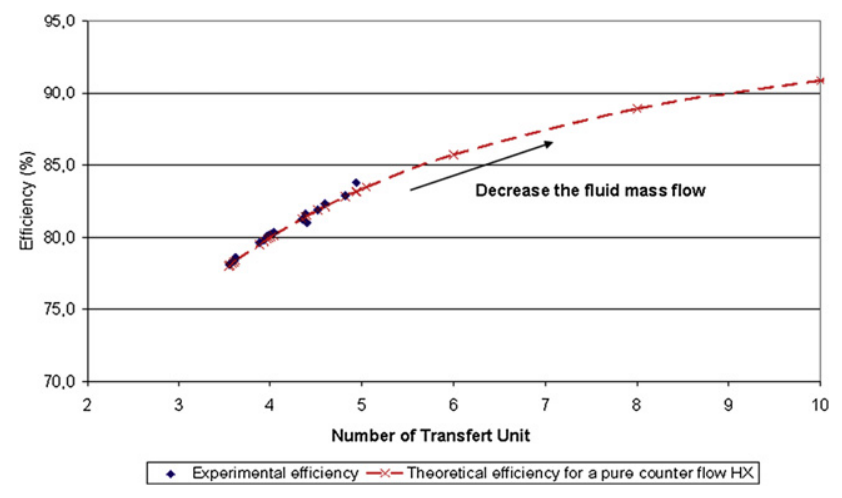

Fig. 3 - Theoretical and experimental thermal efficiency versus the number of transfer units for the SiC heat exchanger prototype fabricated within the project Hycycles. The conditions for the experimental runs were as follows: mass flow rate 5-30 g/s of air, inlet cold temperature ranging from 80 to $160{ }^{\circ} \mathrm{C}$ and inlet cold temperature ranging from 110 to $300{ }^{\circ} \mathrm{C}$. The inlet hot air temperature was set. A maximum inlet temperature of $860{ }^{\circ} \mathrm{C}$ was applied corresponding to a cold inlet temperature of $300{ }^{\circ} \mathrm{C}$. The total testing time was 30 days.

characteristics and the effective transport properties of the foam [14]. These effective transport properties have been incorporated in a continuum reactor model developed by spatial averaging the governing equation in the fluid and solid phases. The model yielded temperature, velocity, pressure and species distribution in the absorbing foam, as well as the energetic and chemical conversion efficiencies [15].

The models were used to provide recommendations on properties of the porous ceramics (porosity, size, inlet of the liquid acid) optimised with respect to the performance of the evaporation and decomposition process. The dynamic behaviour of the decomposer was simulated to develop control strategies for the operation of the solar reactor.

\subsection{Separator for the $\mathrm{H}_{2} \mathrm{SO}_{4}$ decomposition products}

The decomposition of $\mathrm{SO}_{3}$ to $\mathrm{SO}_{2}$ is thermodynamically unfavourable at lower temperatures, and so is carried out at temperatures above $800{ }^{\circ} \mathrm{C}$ in order to produce a sensible equilibrium conversion. Le Chatelier's principle suggests that oxygen removal will shift the equilibrium in favour of increased decomposition. Identifying suitable methods for carrying out this separation is complicated by the lack of membrane materials able to withstand the severe process conditions involved. Work on this subject investigated dense oxygen transport membranes, made from novel ceramics, evaluating their suitability to the $\mathrm{H}_{2} \mathrm{SO}_{4}$ decomposition section.

Based on the results of equilibrium calculations yttriastabilised zirconia (YSZ) was considered to be a good candidate material and therefore investigated in depth. Experimental stability and permeation testing of the membranes was carried out using a high temperature membrane cell held within a furnace at temperatures between $700{ }^{\circ} \mathrm{C}$ and $900{ }^{\circ} \mathrm{C}$.

When $\mathrm{SO}_{2}$ is introduced into the feed stream, a sharp decrease in oxygen flux is observed. AC impedance spectroscopy and X-ray diffraction (XRD) indicate that the bulk YSZ was unaffected by exposure to $\mathrm{SO}_{2}$, however a surface layer was created. X-ray Photoelectron Spectroscopy (XPS) shows the presence of sulphur on the electrode surface following $\mathrm{SO}_{2}$ exposure. The reduction in performance has therefore been attributed to adsorption of $\mathrm{SO}_{2}$ on to the electrode and YSZ surfaces.

A series of experiments were carried out with an external high voltage pulse being applied during the $\mathrm{SO}_{2}$ exposure period. The conditions applied were the following: operation temperature of $850^{\circ} \mathrm{C}$ was reached at a ramp of $5^{\circ} \mathrm{C} / \mathrm{min}$. Gas mixtures composed of oxygen $(5 \mathrm{ml} / \mathrm{min})$ and helium $(45 \mathrm{ml} /$ $\mathrm{min}$ ) were passed through an upper quartz tube for pre-heating. An external voltage of $1.5 \mathrm{~V}$ was applied. Current flow and oxygen concentration in permeate side were measured. After around 1-h of steady state membrane performance, the composition of the feed stream was changed to oxygen $(5 \mathrm{ml} / \mathrm{min})$, helium (30 ml/min) and sulphur dioxide (15 ml/min). Oxygen still permeated through the membrane to the anode side while helium and sulphur dioxide did not. During the whole run, the overall flow rate of the feed stream was $50 \mathrm{ml} / \mathrm{min}$ and oxygen accounted for $10 \%$. All the flow rates were controlled by rotameters. The first run involved $1 \mathrm{~h} \mathrm{SO} \mathrm{S}_{2}$ free period (feed: $\mathrm{O}_{2}$ and $\mathrm{He}$ ) and $2 \mathrm{~h} \mathrm{SO}_{2}$ exposure period (feed: $\mathrm{O}_{2}, \mathrm{He}$ and $\mathrm{SO}_{2}$ ) with a constant external DC voltage of $1.5 \mathrm{~V}$. Afterwards, an experiment was carried out with one 2-min $4 \mathrm{~V}$ pulse for around $75 \mathrm{~min}$ after $\mathrm{SO}_{2}$ was added. Similarly to the $4 \mathrm{~V}$ pulse test, eight
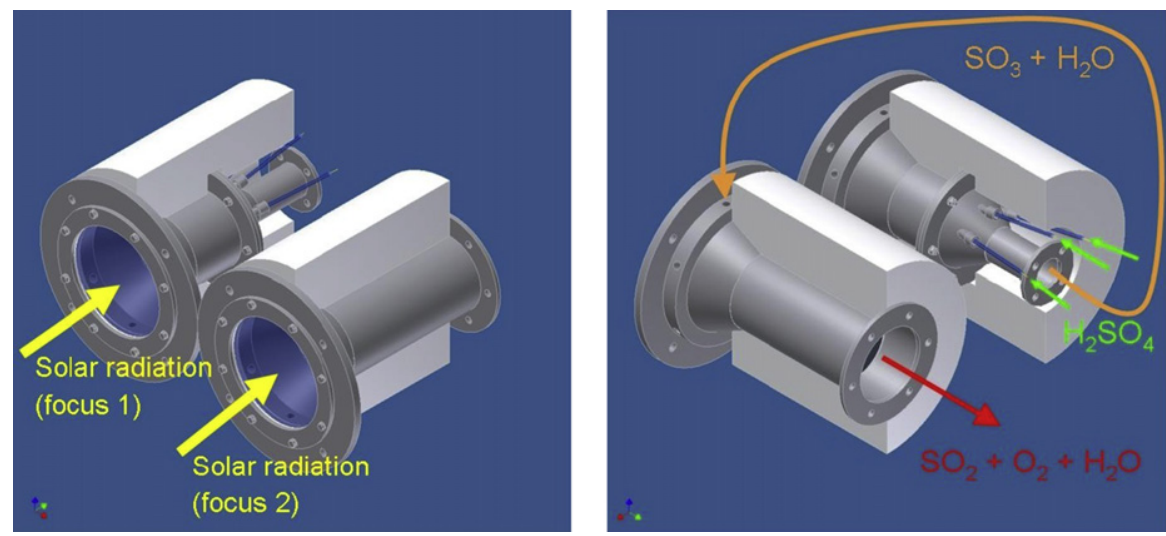

Fig. 4 - Front (left) and rear view (right) of the HycycleS multi-chamber solar reactor: focus 1 - evaporator; focus 2 - decomposer. 
more experiments were conducted with different magnitude pulses (i.e. 2.0, 3.0, 3.5, 4.0, 4.5, 5.0, 5.5, $6.0 \mathrm{~V}$ ).

The results are shown in Fig. 5. A rapid decrease in current and permeate oxygen concentration following the addition of $\mathrm{SO}_{2}$ is seen as before. Following the initial rapid decrease, the current and permeate oxygen concentration decreased slowly and gradually until the high potential was applied. The current and permeate oxygen concentration increased after the voltage pulse, indicating a partial recovery in membrane performance [16].

It can be concluded that YSZ conducts oxygen in the presence of $\mathrm{SO}_{2}$ at $800-900{ }^{\circ} \mathrm{C}$, however a degradation in performance is observed when $\mathrm{SO}_{2}$ is introduced into the feed stream. This degradation mechanism has been identified as absorption of $\mathrm{SO}_{2}$ on to platinum electrodes, which reduces the oxygen flux. Variation of the applied voltage only partially regenerates the performance. Fluxes through the membranes tested are low for practical purposes and thinner membranes are required. In conclusion, the technology has promise, however improved performance is required and this relies on improved production processes.
In parallel a conventional oxygen separator was considered and investigated as well. The necessary materials information, in terms of reliable thermodynamic data on the equilibrium between oxygen and the solutions of $\mathrm{SO}_{3}$ and $\mathrm{SO}_{2}$ downstream of the decomposition reactor, do not exist in the literature and yet represent a major obstacle to the immediate design of an operating cycle. The objectives of this task were to measure multi-component equilibrium data for $\mathrm{SO}_{2}$, oxygen and water and to develop models to allow prediction of the relevant properties. Thermodynamic modelling of the binary $\mathrm{SO}_{2}-\mathrm{H}_{2} \mathrm{O}$ and multicomponent $\mathrm{SO}_{2}-\mathrm{H}_{2} \mathrm{O}-\mathrm{O}_{2}$ systems has been accomplished for that purpose and the experimental programme is designed to provide data points to verify the thermodynamic models created. Over 100 experiments at temperatures ranging from 20 to $80^{\circ} \mathrm{C}$ have been conducted in a designated apparatus on both the binary and ternary systems [17].

A large database of experimental results for both the binary and ternary systems has been created. This will enable a scientific-based design of the low temperature separator to be achieved and will also be of use to future modellers.

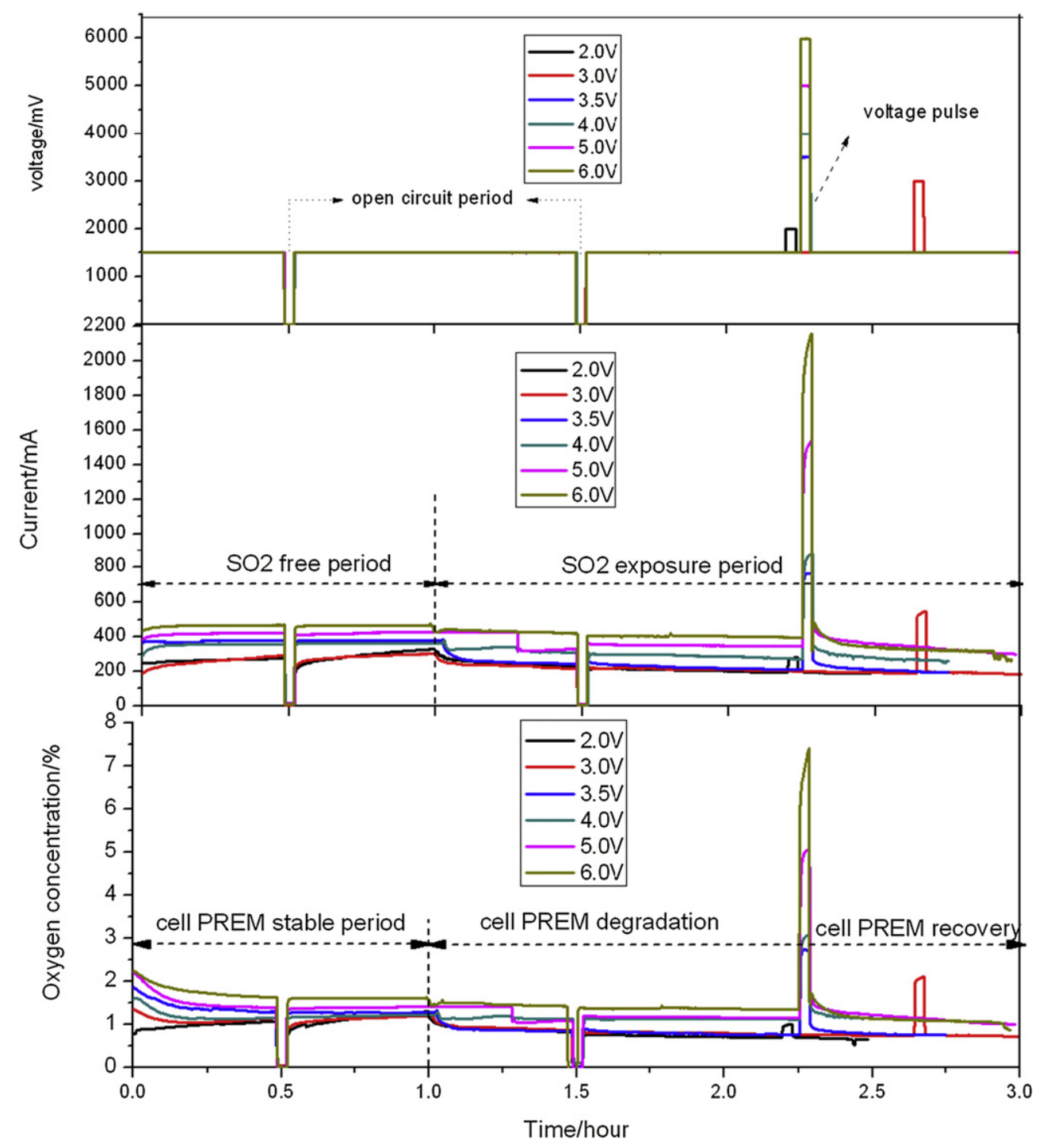

Fig. 5 - Experimental data for exposure of YSZ/Pt pellet to $\mathrm{SO}_{2}$ and $\mathrm{O}_{2}$ at $850{ }^{\circ} \mathrm{C}$ (with different potential pulse treatment). 


\subsection{Scale-up and demonstration scenario}

A demonstration scenario of a solar powered hybrid sulphur cycle process has been elaborated. The scenario considered foresees the multiplication of individual receiver-modules in an area-wide arrangement and the integration of the main parts and of most components of a HyS chemical hydrogen production plant into the housing of dedicated solar tower system. A promising option is to arrange the units and components of a plant, according to an arrangement similar the one depicted in Fig. 6.

The concept was to integrate as many as possible units in the tower housing to keep distances, pipe lengths and space demand minimum. The concept is derived from the Solar Power Tower in Julich. In particular, the minimisation of pipe length is of high importance to reduce heat losses and to limit the amount of expensive corrosion resistant materials needed for some of those pipes. Different units are installed at different storeys of the tower building. As a dominating principle, the temperature of the media used and operation temperature of the units decreases from the top storey to the ground floor - again in order to minimise losses and pipe lengths. The suggested plant arrangement and geometry makes sense for plants in a range of up to 10-15 MW. This range includes the typical sizes of demonstration activities in
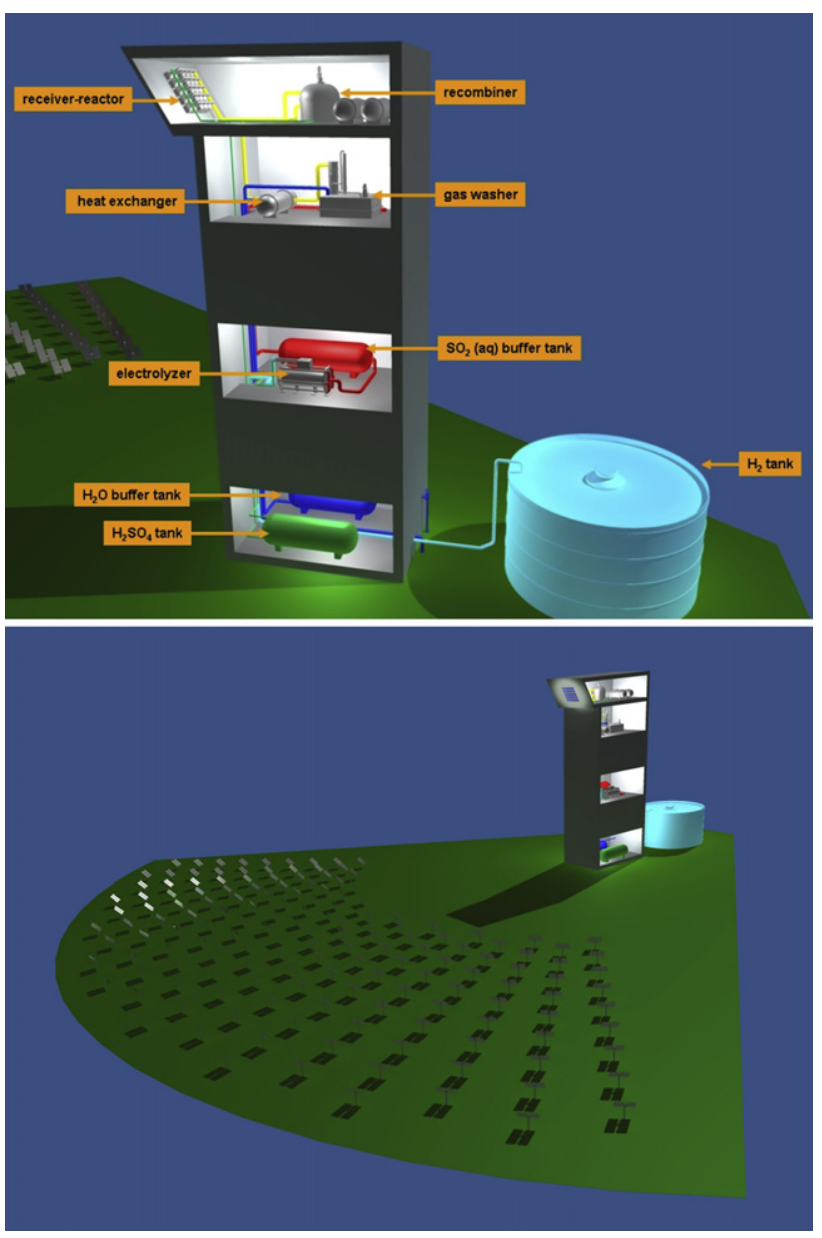

Fig. 6 - HyS process integrated into a central receiver system. the field of concentrated solar power generation (CSP). Larger, commercial plants would rather raise the need to integrate the chemical part of the process in an additional building, since the components will be too big to be integrated into the solar tower building.

\section{Conclusions}

The project HycycleS puts its emphasis on materials and components for $\mathrm{H}_{2} \mathrm{SO}_{4}$ evaporation, decomposition, and $\mathrm{SO}_{2}$ separation. The suitability of materials and components was demonstrated by decomposing $\mathrm{H}_{2} \mathrm{SO}_{4}$ and separating its decomposition products in scalable prototypes.

Silicon Carbide ( $\mathrm{SiC}$ ) turned out as the material of choice for the components facing the most corrosive environment of the process: the $\mathrm{H}_{2} \mathrm{SO}_{4}$ evaporator and decomposer. The mechanical properties of representative specimen are not significantly affected by the corrosion process.

Candidate catalysts for the high temperature reduction of $\mathrm{SO}_{3}$ have been screened and analysed - mainly considering oxides of transition metals. Their catalytic activity and their durability have been investigated and quantified experimentally. The systematic studies on the quantitative evaluation of the catalytic activity, durability, stability, and the exsitu post-characterisation revealed that a $\mathrm{Cr}-\mathrm{Fe}$ mixed oxide $\left(\mathrm{Fe}_{0.7} \mathrm{Cr}_{1.3} \mathrm{O}_{3}\right)$ is the most promising material among the ones examined.

Based on the use of the highlighted construction and catalyst materials prototype decomposers have been developed and tested. The successful fabrication and testing of a large size heat exchanger/reactor prototype composed of SiC plates shows promise with respect to its use for sulphuric acid decomposition in the SI and HyS cycle. This prototype represents one of the largest ceramic heat exchangers ever realised.

A solar specific decomposer prototype was realised and tested on sun in a solar furnace, which proved the practicability and suitability of all reactor components. Moreover, sulphuric acid was successfully decomposed to provide the required $\mathrm{SO}_{2}$ product with yields of up to $90 \%$ of the respective thermodynamic value and with reactor efficiencies of up to $40 \%$.

A novel approach of using dense oxygen transport membranes, made from novel and complex ceramics, for oxygen removal from the $\mathrm{H}_{2} \mathrm{SO}_{4}$ decomposition product in order to shift the equilibrium in favour of increased decomposition was investigated. The YSZ-based membranes stability and performance for carrying out this separation turned out not sufficient for practical application.

A conventional oxygen separator, a low-temperature wet scrubbing system, was addressed as well. A large database of experimental results for both the binary and ternary systems has been created, and in particular for the low temperature Vapour Liquid Equilibria of the $\mathrm{SO}_{2}-\mathrm{H}_{2} \mathrm{O}-\mathrm{O}_{2}$ system. This will enable a scientific based design of the low temperature separator to be achieved.

A demonstration scenario has been depicted and analysed which foresees the multiplication of individual receivermodules in an area-wide arrangement and the integration of all necessary components of a HyS chemical hydrogen production plant in a dedicated Megawatt-scale solar tower system. 


\section{Acknowledgement}

The authors acknowledge the co-funding of the European Commission for the project Hycycles (Contract-No. 212470) in the 7th Framework Programme.

\section{REFERENCES}

[1] Eisenstadt MM, Cox KE. Hydrogen production from solar energy. Solar Energy 1975;17:59-65.

[2] Kolb GJ, Diver RB. Screening analysis of solar thermochemical hydrogen concepts. SANDIA report SAND2008-1900; March 2008.

[3] Brecher LE, Spewock S, Warde CJ. The Westinghouse sulfur cycle for the thermochemical decomposition of water. In: 1st World Hydrogen Energy Conference, Miami Beach, Florida, USA, conference proceedings, vol. 1; 1976.

[4] Schuster JR. Status of thermochemical water-splitting development at general atomics. GA report GA-A14666. General Atomics; 1977.

[5] Corgnale C, Summers WA. Solar hydrogen production by the hybrid sulfur process. Int J Hydrogen Energy 2011;36: 11604-22619.

[6] Perret R, Chen Y, Besenbruch G, Diver RB, Weimer A, Lewandowski A, et al. DOE Hydrogen Program. Annual progress report. U.S. Department of Energy, IV.I.1 Solar Hydrogen Generation Research; 2005. p. 377.

[7] Nishiyama N, Futakawa M, Ioka I, Onuki K, Shimizu S. Corrosion resistance evaluation of brittle materials in boiling sulphuric acid. J Soc Mat Sci 1999;48:746-52.

[8] Thomey D, Roeb M, de Oliveira L, Gumpinger T, Schmücker $\mathrm{M}$, Sattler C, et al. Characterisation of construction and catalyst materials for solar thermochemical hydrogen production. In: 1st Int. Conf. on Materials for Energy (EnMat 2010), July 4-8, 2010, Karlsruhe, Germany.

[9] Kargiannakis G, Agrafiotis C, Zygogianni A, Pagkoura C, Konstandopoulos AG. Hydrogen production via sulfur-based thermochemical cycles: part 1: synthesis and evaluation of metal oxide-based candidate catalyst powders for the sulfuric acid decomposition step. Int J Hydrogen Energy 2011; 36:2831-44.

[10] Tagawa H, Endo T. Catalytic decomposition of sulfuric acid using metal oxides as the oxygen generating reaction in thermochemical water splitting process. Int J Hydrogen Energy 1989;14:11-7.

[11] Kargiannakis G, Agrafiotis C, Pagkoura C, Konstandopoulos AG, Thomey D, de Oliveira L, et al. Hydrogen production via sulfur-based thermochemical cycles: part 3: durability and post-characterization of silicon carbide honeycomb substrates coated with metal oxidebased candidate catalysts for the sulfuric acid decomposition step. Int J Hydrogen Energy 2012;37:8190-203.

[12] Noglik A, Roeb M, Sattler C, Pitz-Paal R. Experimental study on sulfur trioxide decomposition in a volumetric solar receiver-reactor. Int J Energy Res 2009;33: 799-812.

[13] Thomey D, de Oliveira L, Säck JP, Roeb M, Sattler C. Development and test of a solar reactor for decomposition of sulphuric acid in thermochemical hydrogen production. Int $J$ Hydrogen Energy 2012;37:16615-22.

[14] Petrasch J, Wyss P, Stämpfli R, Steinfeld A. Tomographybased multiscale analyses of the 3D geometrical morphology of reticulated porous ceramics. J Am Ceramic Soc 2008;91: 2659-65.

[15] Haussener S, Thomey D, Roeb M, Steinfeld A. Multi-scale modelling of a solar reactor for the high-temperature step of a sulphur-iodine-based water splitting cycle. In: ASME Energy Sustainability Conference, August 2011, Washington D.C., USA.

[16] Atkin I, Elder RH, Priestman GH, Sinclair DC, Allen RWK. High temperature oxygen separation for the sulphur family of thermochemical cycles - part I: membrane selection and flux testing. Int J Hydrogen Energy 2011;36: 10614-25.

[17] Shaw AC, Romero MA, Elder RH, Ewan BCR, Allen RWK. Measurements of the solubility of sulphur dioxide in water for the sulphur family of thermochemical cycles. Int J Hydrogen Energy 2011;36:4749-56. 